\title{
Assessing the determinants of safety culture in the maritime industry
}

\author{
Daniela Andrei \\ Curtin University \\ daniela.andrei@curtin.edu.au \\ Michelle R Grech \\ Australian Maritime Safety Authority \\ michelle.grech@amsa.gov.au \\ Mark Griffin \\ Curtin University \\ mark.griffin@curtin.edu.au \\ Andrew Neal \\ University of Queensland \\ a.neal@psy.uq.edu.au
}

\begin{abstract}
The study approach, findings and the way forward on an Australian Linkage Council funded collaborative research project between the University of Queensland, University of Western Australia and the Australian Maritime Safety Authority, focusing on safety culture will be presented. The aim of the study was to identify the factors that have the strongest impact on safety on board international vessels operating in Australian waters, in order to provide recommendations on how to improve safety in the maritime industry. More than 1,000 seafarers from 197 ships comprising 23 flag States were surveyed. The survey assessed safety culture, work demands, fatigue, mental health, and well-being and safety performance. The results are being used to develop a set of recommendations regarding the best ways to improve safety on board ships. The recommendations centre on a) improving the quality of work procedures; $b$ ) introduction of effective fatigue management systems; and c) improving the quality of work design and organisational support. The findings of this study have been presented at a range of industry forums, briefings, and at the International Maritime Organization.
\end{abstract}

\section{INTRODUCTION}

\section{Safety Climate, Safety Culture, Behaviour and Outcomes}

The term "safety culture" refers to the way that an organisation manages safety, and reflects the core beliefs and attitudes that guide behaviour and decision-making (Casey, Griffin, Flatau Harrison \& Neal, 2017). There are two broad elements of safety culture. The first are the policies, practices and procedures that the organisation has for managing safety. This first element is sometimes referred to as "safety climate" within the academic literature (Griffin \& Neal, 2000; Neal, Griffin, \& Hart, 2000). The second are the values, priorities, norms and motives held by people in the organisation. These two elements reflect the distinction between safety culture as something that an organisation has (i.e., policies, practices \& procedures) and safety climate as something that an organisation is (i.e., people with a shared 
set of values and beliefs). Measures of safety climate and culture are highly correlated, and are not distinguishable for practical purposes (Casey, et al., 2017). In this report, we use the term "safety culture" rather than "safety climate", because it is a broader term, and is more widely recognized within the maritime industry.

In a recent review, Lützhöft, Grech \& Porathe. (2011) identified safety culture as a critical risk factor for the maritime industry. They argued that whilst most accidents at sea are caused by human error, these errors are attributable to conditions created by the organisation. Specifically, safety-related policies and practices relating to communication, commitment, trust, incident reporting, risk management and training play an important role in shaping behaviour, which can either directly or indirectly affect safety. According to Lützhöft et al. (2011) maritime safety culture is a concern, because shipping operators are under significant cost pressures. While there is anecdotal evidence suggesting that maritime safety culture is a critical risk factor, research on maritime safety culture is limited and fragmented. Recent work indicates that the relationship that exists between safety culture, safety behaviour and safety outcomes observed in other high-risk industries may also exist within the maritime industry. While this evidence is encouraging more is needed to clarify the role of safety culture in the maritime industry, particularly in relation to seafarers aboard vessels operating in Australian waters. The remoteness of the work environment also creates other concerns with crew having limited social contact and may be isolated for long periods of time with little support, all of which can reduce performance, health and well-being (Oliver, Cheyne, Tomas, \& Cox, 2002). Hence this study also included an evaluation of seafarer mental health and wellbeing in the context of safety culture.

The aim of the study was to identify the factors that have the strongest impact on safety on board international vessels operating in Australian waters, in order to provide recommendations on how to improve safety in the maritime industry. This paper presents a selection of the findings with a full report available upon request.

\section{RESEARCH METHOD}

\section{Measures}

For the purpose of this study the Developmental Safety Culture Survey (DSCS) developed by the research team was used to measure different levels of safety culture development. The DSCS distinguishes between different levels of safety culture development based on existing theory (Lawrie, Parker, \& Hudson, 2006, Reason, 1997) and was validated during the pilot study. Twelve items were developed to tap into the "Systems and Processes" and "People" aspects of safety culture. An overview of the measurement model is presented in figure 1. The aspects measured in the "Systems and Processes" section included:

- Safety policies and procedures,

- Safety training,

- Communication,

- Role definitions,

- Reporting systems, and

- Operational schedules.

The "People" aspects included:

- Safety Values, 
- Norms, and

- Motives.

Based on the existing literature three specific descriptors were developed to reflect:

1. dysfunctional/reactive safety culture;

2. compliance oriented culture, and

3. participative/generative safety culture.

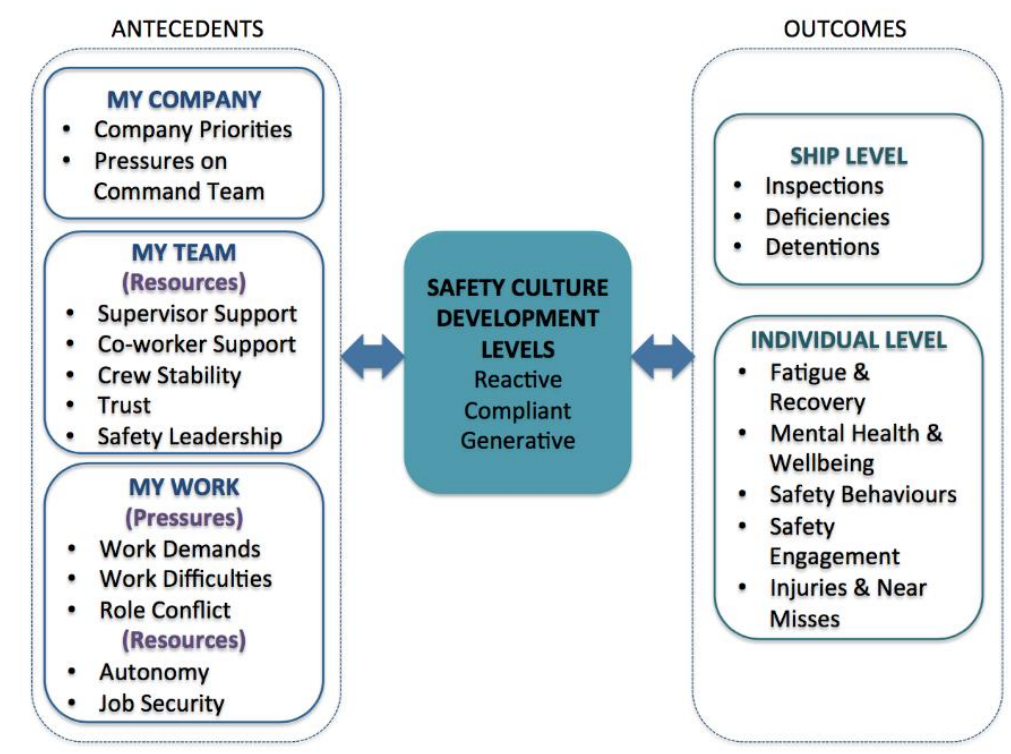

Figure 1: Overview of the overall measurement approach and variables included in this study.

Participants responded on a 5-point Likert scale, where 1 received descriptors that reflected a reactive safety culture and 5 represented descriptors that reflected a participative/generative safety culture. Participants indicated the value that best reflects the way each aspect was being managed on their ship. The survey also included a series of individual and work demographic questions. Examples of individual level factors included fatigue and recovery with participants quality of sleep also assessed by asking whether they experienced sleep problems onboard the ship. Beyond the general measures of compliance, the quality of safety behaviours were analysed by looking at two types of positive compliance behaviours: adaptive compliance and deep compliance; and two types of negative safety behaviours: surface compliance and non-compliance.

\section{Procedure}

Participation in the study was voluntary and anonymity was guaranteed. The option of electronic and paper based surveys was provided. Partnerships with various organisations with direct contact to ships and seafarers were developed to increase survey reach. These included training providers, AMSA inspectors, pilots and seafarer welfare centres.

\section{Participants}

The final sample consisted of 1026 seafarers. 164 participants completed the command team survey and 862 participants filled in the survey for the rest of the crew. The difference in surveys were related to work pressure, safety behaviours and safety engagement questions. For the Command Team, the work pressure measures were supplemented with an extra 
measure of role conflict arising from their critical position as mediators between company and crew. The safety behaviours and safety engagement measures had different referents in which the Command Team were asked to provide an overall assessment of their crew behaviours using the same items, while the crew were required to only report on their own work behaviours and safety engagement.

$97.9 \%$ of the participants were male with an average age of 34.7 years ( $S D=10.4$ years). The age range for $57.8 \%$ of the participants was between 18 to 37 years. Participants were mostly experienced seafarers, with an average overall tenure at sea of around 10 years $(M=9.76$, $S D=8.78$ years at sea). Most participants worked long contracts - in the region of 9 months to 1 year, especially evident for the officers and ratings. Most participants reported 4 months or less onboard the ship, with very few having been onboard for more than 9 months. The sample was represented by more than 16 nationalities with most of the participants coming from the Philippines. Participants were also asked to report how many different nationalities were on board their ship. On average, participants indicated that there were about 4 different nationalities on board the ship they were working on.

\section{Ship level data}

All responses from seafarers on the same ship, identified by its IMO number, were averaged to obtain an overall score for the ship. 195 distinct ships were identified across the sample. The ships were then categorised into the following ship types (Figure 2).

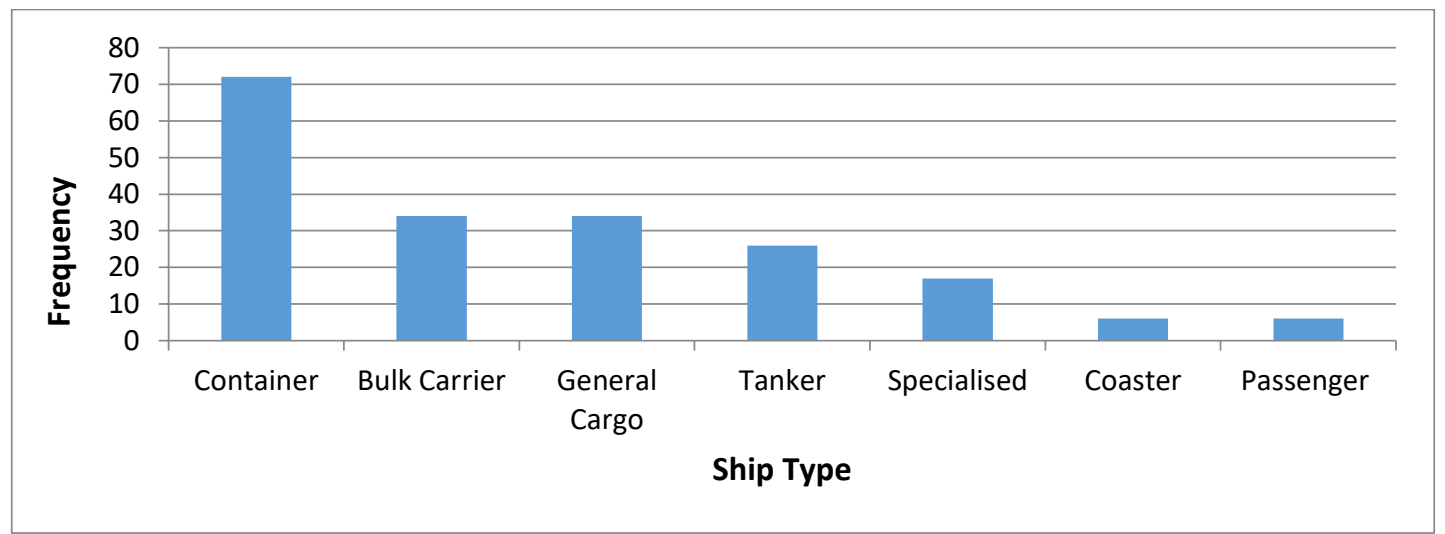

Figure 2. Type of ships surveyed.

The breakdown of Flag States represented in this study was fairly consistent with the flag state population of vessels coming into Australian ports during the same year this survey was conducted. Panama $(N=30)$ was the most frequently represented, followed by Singapore $(N=27)$, Hong Kong $(N=22)$, Liberia $(N=20)$, Malta $(N=13)$, Marshall Islands $(N=12)$, Australia $(N=11)$ and Bahamas $(N=10)$.

\section{Data analysis and reporting}

Using SPSS statistical analyses tool the data were analysed at two distinct levels. First, an analysis was carried out at the individual level, taking into consideration the main differences and associations between responses offered by individual seafarers. The, data were analysed at the ship level by aggregating all individual responses from the same ship. Cross-level interactions were also investigated in order to identify the effects of broader (ship level) 
factors on individual outcomes. The results highlight the strengths and weaknesses of safety culture, as well as its possible antecedents and consequences within the sample.

Due to increased pressures and uncertainty in the industry and the possible increased relevance of priorities communicated by companies, a multi-level analysis was also performed to investigate more closely the way perceptions of company priorities and operational uncertainty at the command team level might explain safety and well-being outcomes for the rest of the crew onboard the ship. The main interest was on the interplay between priority on safety and costs, but operational uncertainty was also added to the model. An overview of the predictors used in this analysis is presented in Figure 3.

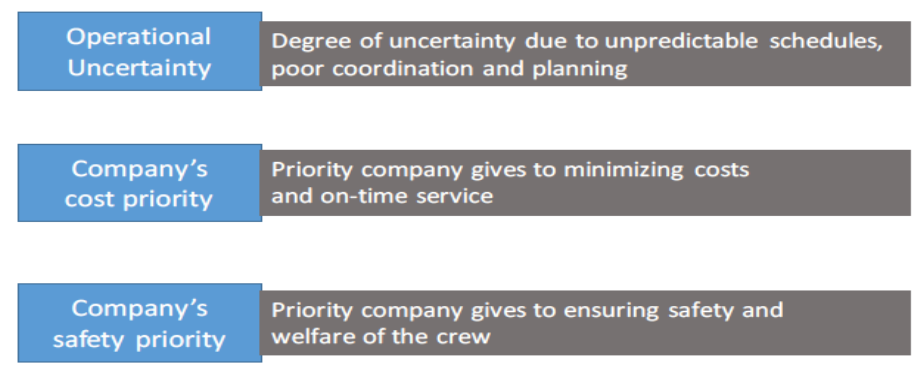

Figure 3. Overview of main predictors used in the multi-level analysis on priorities, operational uncertainty and their effects on safety and wellbeing.

At the ship level of the multi-level model, priorities and operational uncertainty were included as perceived by members of the command team. The reasoning was twofold. First, company priorities are usually communicated to seafarers by the command team onboard the ship which inform their decisions and management on the crew. Second, from a methodological perspective, using two different sources for the different data: the command team for priorities and operational uncertainty, and the rest of the crew for wellbeing and safety outcomes ensures more robust results.

\section{FINDINGS and DISCUSSION}

\section{Safety Culture and its antecedents}

Figure 4 shows the results of how participants evaluated safety culture across ships. Aspects that were most positively evaluated were those related to seafarers' perceived personal responsibility towards safety: responsibilities and motives. Although the overall findings show that safety culture was evaluated positively, there were still a number of cases for which safety culture was reported within the reactive-compliance based spectrum such as the Planning and Scheduling dimension. In addition, although formal mandatory requirements such as the International Safety Management Code are expected to have a positive impact on the evaluation of perception of systems and processes, it is also important to understand how these formal systems have an impact on safety behaviour and wellbeing of seafarers. 


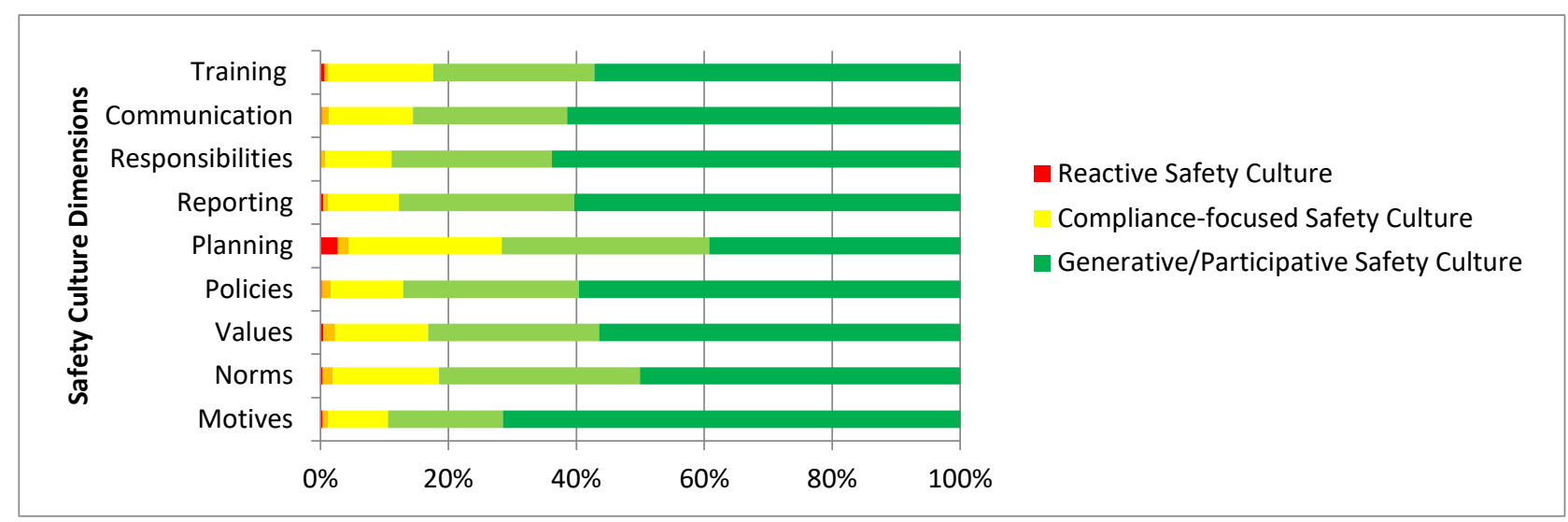

Figure 4 Breakdown of participants' responses on the SCDS dimensions.

Figure 5 presents an overview of how company priorities are perceived. Overall, seafarers perceive that companies place a great importance on preventing damage to the ship and cargo, as well as on the safety of the crew. However, about $20 \%$ of seafarers perceive that the company they work for places little or moderate importance on their welfare.

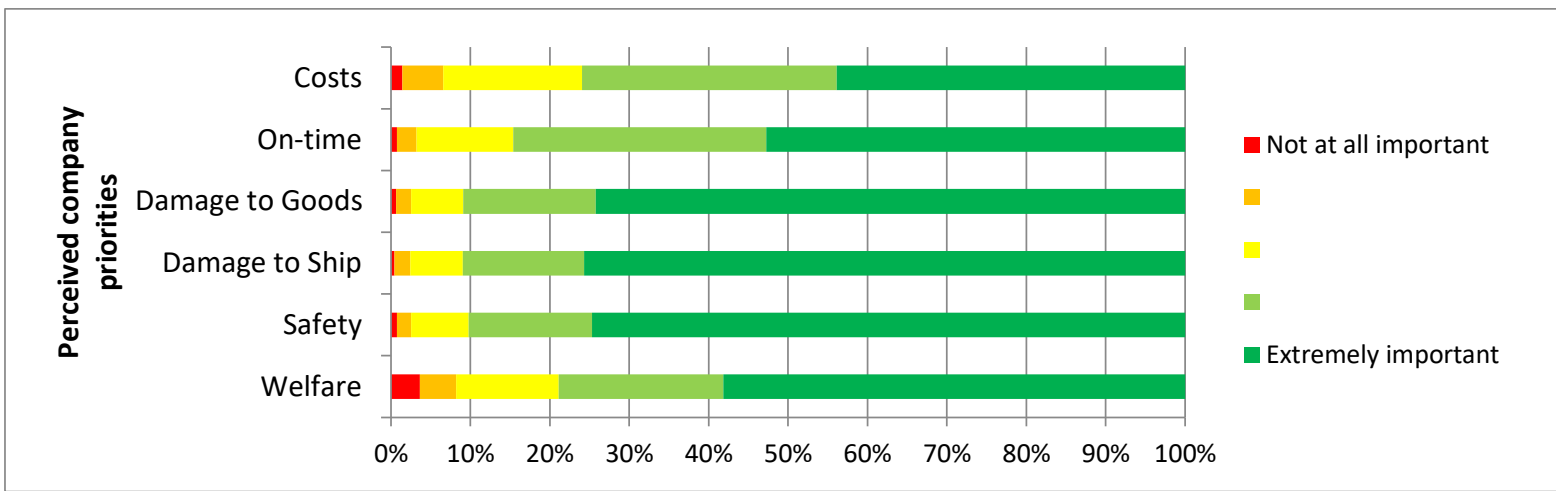

Figure 5. Breakdown of participants' responses on perceived company priorities items.

\section{Work Demands}

Participants reported working a average of 61.28 hours per week, with a standard deviation of 13.06 hours. The results indicate that a high proportion (almost $30 \%$ ) of the participants are working long hours, exceeding 69 hours/week. Long working hours appear to be also coupled with increased work pressures and demands. More than $20 \%$ of participants reported that their working hours are unpredictable. Similarly, approximately $40 \%$ of participants reported working under time pressure, and about half of them reported experiencing high demands for vigilance at least sometimes in their work.

\section{Work Difficulties}

Descriptive data on the three types of shipboard conditions (work difficulties) that might affect safety culture and safety outcomes: physical conditions, technology and resources, and operational uncertainty were analysed. Two categories of physical conditions were measured: external (weather, visibility and ship motion) and internal conditions (see Figure 6). Approximately $40 \%$ of participants reported that bad weather often caused difficulties in performing their work. Additionally, more than $20 \%$ of participants reported that poor visibility and ship motion often created difficulties for them in performing their work. Results 
for internal physical working conditions were similar (Figure 6), with loud noise and cramped workspaces being reported as a source of frequent disturbance by a high proportion of participants.

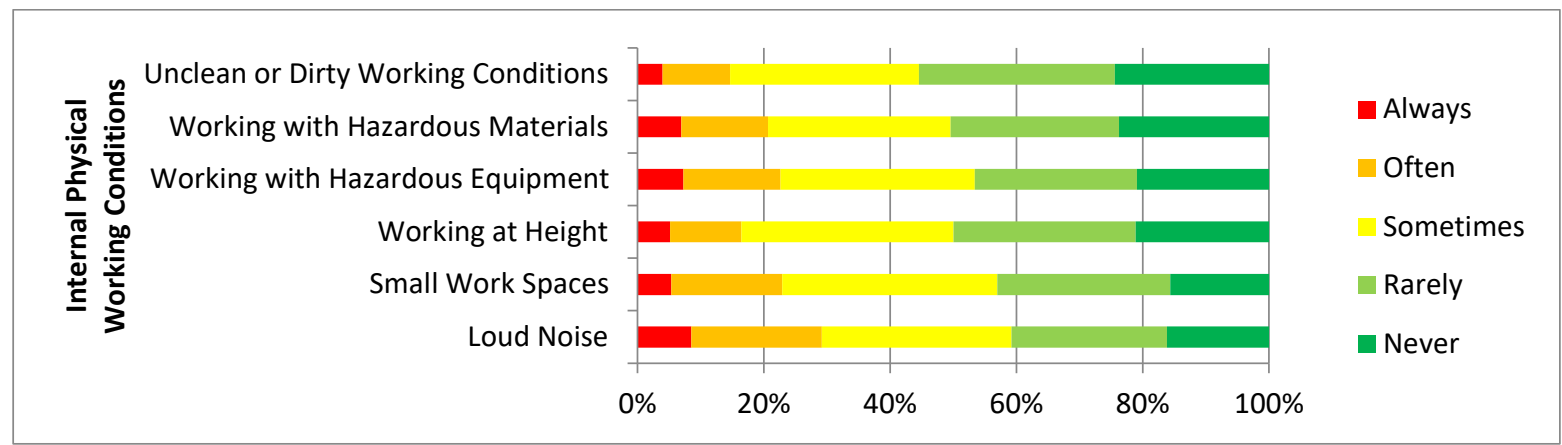

Figure 6. Breakdown of participants' responses evaluating how often internal physical conditions are creating difficulties for them in their work.

Scores for difficulties related to technology and resources were relatively homogenous. However, more participants (around 20\%) reported that not having the needed supplies, and maintenance problems often created difficulties in performing work (Figure 7).

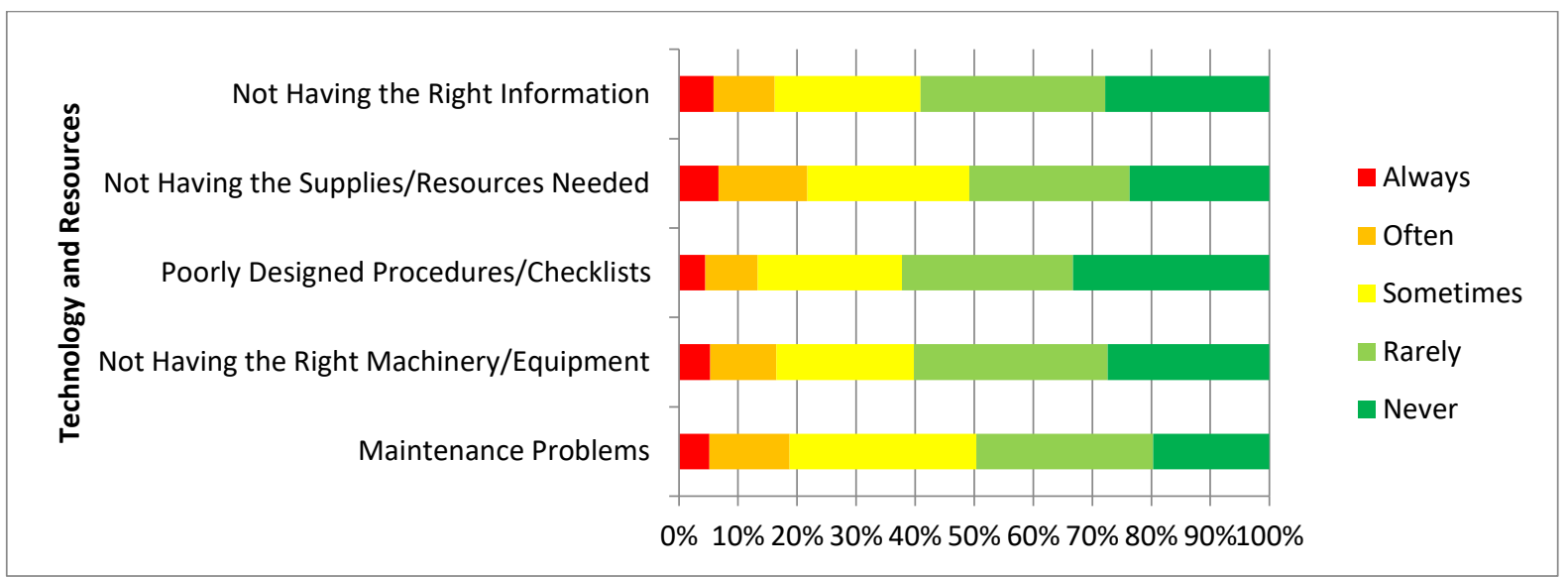

Figure 7. Breakdown of participants' responses evaluating how often conditions related to available technology and resources are creating difficulties for them in their work.

Approximately $40 \%$ of the sample reported difficulties related to operational uncertainty at least sometimes in their work. Scores are relatively homogenous across the factors measured, but frequent changes to schedule and manifest as well as disruptions or delays appear to be more common forms of difficulties (Figure 8). 


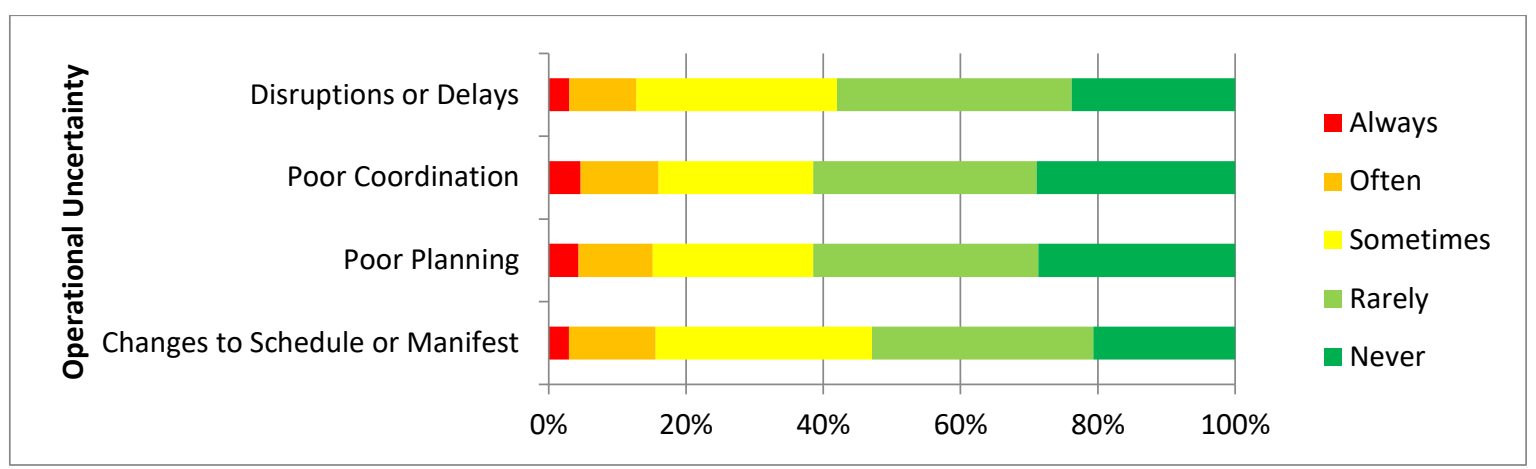

Figure 8. Breakdown of participants' responses evaluating how often conditions related to operational uncertainty are creating difficulties for them in their work.

\section{Safety Leadership}

Four different aspects of safety leadership were measured: leverage, energise, adapt and defend. Overall, all aspects of safety leadership received positive evaluations, with over $80 \%$ of participants agreeing that their supervisors exhibit all four of the surveyed safety leadership behaviours. It is indicated that the way leaders reflect and communicate safety goals, represents another type of work resource which plays an important role in health and safety outcomes.

\section{Outcomes - Fatigue}

Approximately $12 \%$ of the participants experienced sleep problems, while close to half of the participants reported no sleep-related difficulties. A similar pattern is observed in the participants' fatigue data (Figure 9). Approximately half of the participants reported experiencing low levels of fatigue, while close to $20 \%$ of the participants reported experiencing increased or high levels of fatigue, more notably, chronic fatigue.

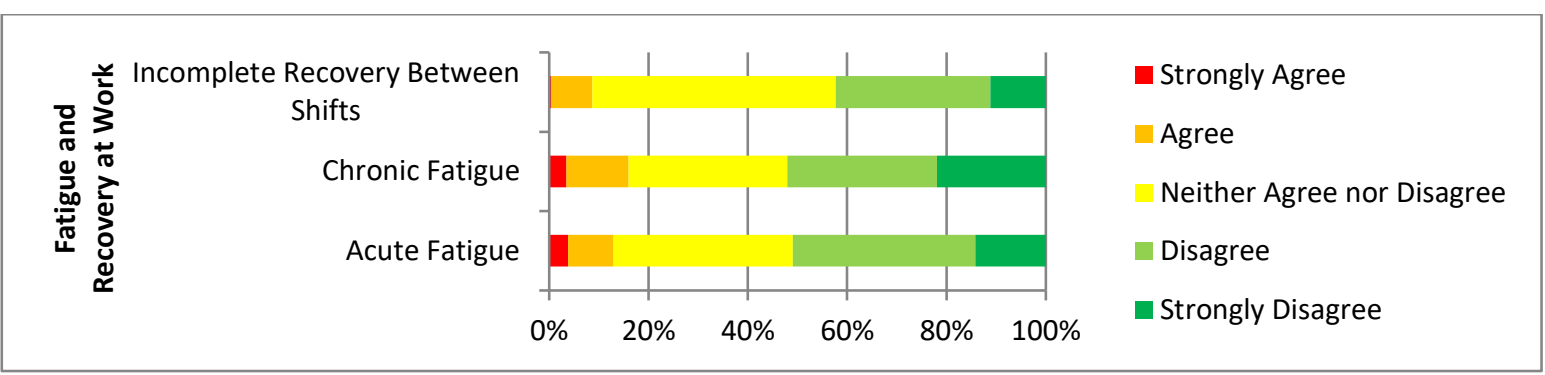

Figure 9. Breakdown of participants' responses regarding experienced levels of fatigue at work.

\section{Outcomes - Mental Health and wellbeing}

Figure 10 presents an overview of mental health and wellbeing. Three aspects of wellbeing were measured: hedonic, psychological and social wellbeing. Almost $40 \%$ of the participating seafarers reported experiencing negative symptoms at least sometimes, and around $10 \%$ of them reported more frequent levels of mental health (frequent symptoms of mental ill health - depression and anxiety). In terms of overall wellbeing, responses were more positive. However, the lowest percentages of wellbeing were found for social wellbeing. Not surprisingly, social wellbeing is the aspect of wellbeing that is more likely to be impacted by the working arrangements in the maritime industry which can be linked to social isolation which is supported by the literature (Iversen, 2012). 


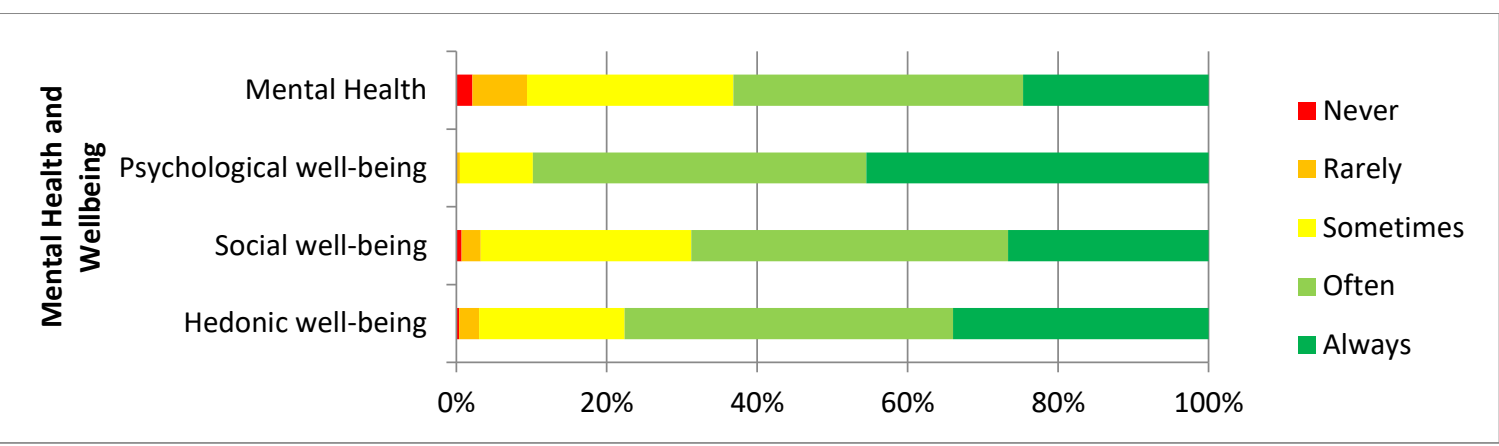

Figure 10. Breakdown of participants' responses regarding mental health and wellbeing.

\section{Outcomes - Overall Safety Behaviours}

Overall safety behaviours were measured in terms of safety task performance, safety participation and safety innovation. High levels of these behaviours were reported, especially for safety task performance. The positive results for safety compliance do not necessarily reflect mature levels of participative/generative safety on board the participating ships. Participative/generative safety cultures are usually associated with less emphasis on overall compliance (safety task performance) and more safety participation and innovation. While safety participation and innovation levels were relatively high in this sample, levels of safety task performance reported were even higher indicating a strong emphasis on compliance.

\section{Outcomes - Types of Safety Compliance}

Figure 11 presents the results for positive compliance behaviours. The results suggest a high level of positive compliance. Most of the participants (approximately $80 \%$ ) reported trying their best to apply the correct procedures to the task (deep compliance) and being adaptive, such as drawing on knowledge and experience to come up with a solution to complete the task safely when circumstances make existing procedures not appropriate (adaptive compliance).

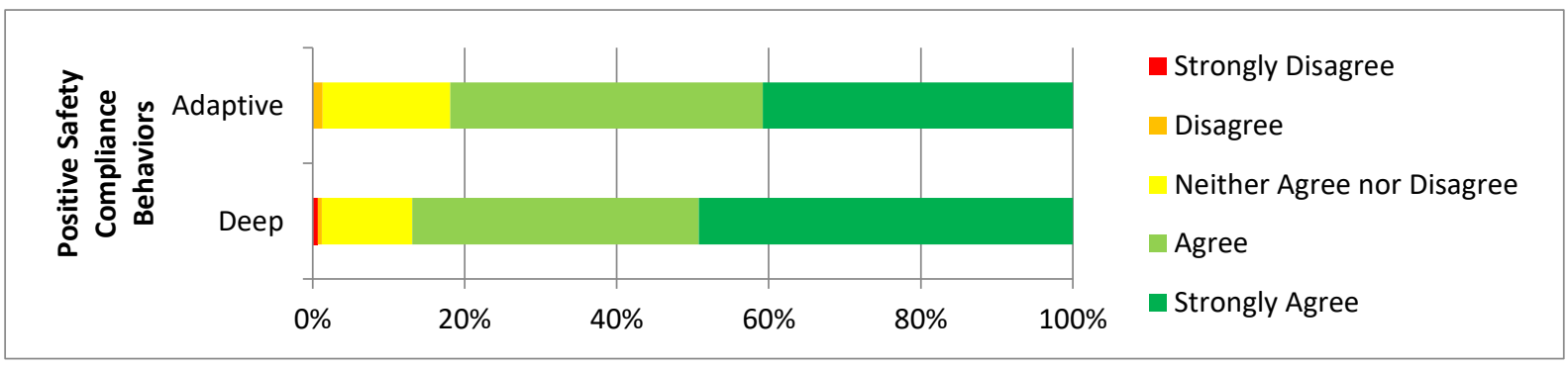

Figure 11. Breakdown of self-reported positive safety compliance behaviours.

However, when negative safety compliance behaviours are taken into account (Figure 12), the results indicate that non-compliance, and especially surface compliance, are also manifested by participants. Notably, more than $40 \%$ of participants reported that they sometimes just "tick the boxes" without paying too much attention to the actual procedures; and almost $20 \%$ reported some level of non-compliant behaviours (e.g. skip the procedures to get the work done). The results for positive and negative safety behaviours might appear contradictory at first glance. However, there are potential explanations for this pattern of findings. In particular, there are multiple procedures in place on any vessel, and seafarers might comply 
with some but not others. Even when overall compliance is positive, there might be situations of non-compliance or surface compliance that have the potential to put safety at risk.

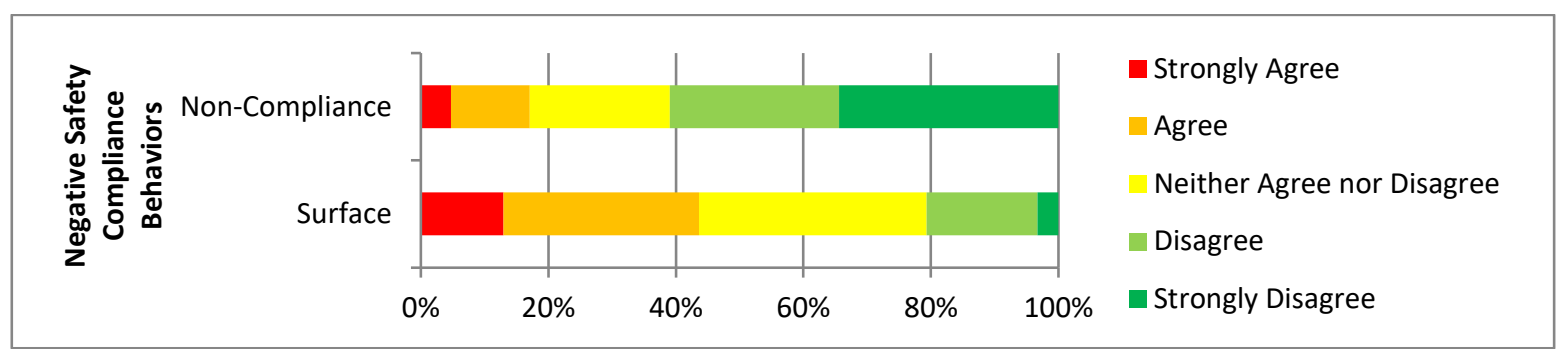

Figure 12. Breakdown of self-reported negative safety compliance behaviours.

\section{Multi-level analysis}

Perceived operational uncertainty, company priorities, and safety in relation to wellbeing and safety compliance outcomes.

The results (Figure 13) indicate that a priority on safety perceived the command team level is not related to either wellbeing or safety compliance at the crew level. However, operational uncertainty and especially a company's priority on costs translate into negative outcomes for seafarers' wellbeing and safety compliance. These results converge toward the conclusion that prioritising costs and increased operational uncertainty might damage both safety and wellbeing, and a sole focus on safety would not be sufficient to counteract these effects.

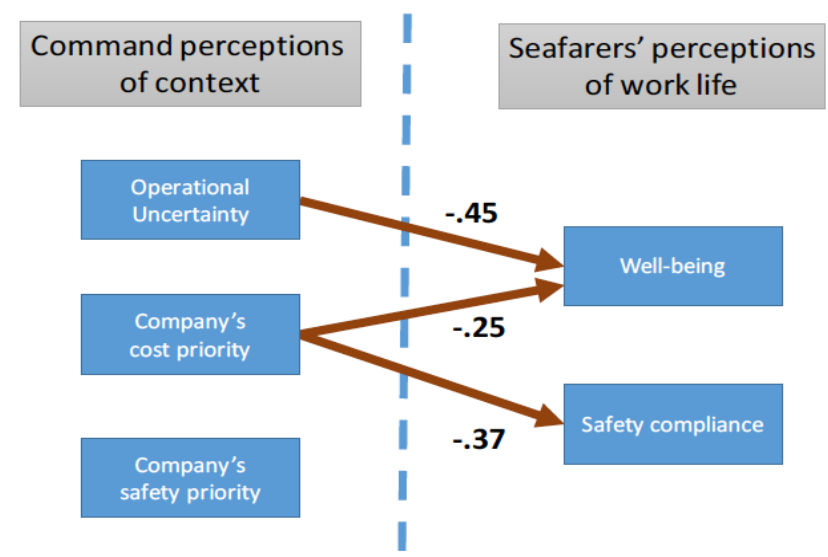

Figure 13. Overview of the multi-level analysis of the effects of perceptions of the overall context at the command team level on safety and wellbeing outcomes for the rest of the crew.

\section{CONCLUSIONS}

Approximately $40 \%$ of this study's sample indicated that they experienced difficulties in performing their tasks due to factors related to technology and resources, such as "poorly designed procedures/checklists" and "not having the right information". Similarly, conversations between seafarers and researchers during data collection revealed that a frequent complaint by seafarers was that there were too many procedures and many were too complicated for effective use. To encourage positive safety behaviours (e.g. deep compliance to safety rules and procedures), seafarers must have the necessary safety knowledge and motivation to perform their task safely, and this is determined, partly, by the degree of clarity and quality of the work procedures. 
More than $20 \%$ of participants reported working more than 69 hours per week and that working hours were unpredictable. Approximately $12 \%$ of the participants reported experiencing sleep problems and $20 \%$ agreed that they experience some level of chronic and similarly $20 \%$ indicated experiencing acute fatigue. Further analyses revealed that chronic fatigue leads to reduced levels of psychological wellbeing that may impact on the overall functioning of employees.

\section{RECOMMENDATIONS}

A number of recommendations were developed based on information gathered from this study. The purpose is to propose research-based practices designed to manage the implications associated with this study's findings. This report focuses on two of these recommendations.

\section{Work and Procedures:}

The important role of the quality of work procedures in predicting compliance is evidenced in studies that show that procedures that were perceived as vague, inappropriate, poorly written or difficult to access were more likely to result in poor compliance (Dahl, Fenstad \& Kongsvik, 2014). Hence, a focus on developing and ensuring high-quality work rules and procedures that are easily understood and are perceived as valid by those to whom they are addressed is critical.

\section{Fatigue Management}

Organisations need to develop fatigue management interventions that continuously monitor and manage fatigue risks to prevent fatigue-related incidents or impaired psychological wellbeing. Managing the risk of fatigue requires a combination of intervention strategies with some being more effective than others. The International Maritime Organization's (IMO) Maritime Safety Committee approved the revised Guidelines on Fatigue (MSC 1598) at its $100^{\text {th }}$ session. Led by Australia, the revision resulted in a more useable guidance document. Central to these guidelines is the concept of a risk-based approach to fatigue management. This includes the approach that since fatigue affects the safe operation of the vessel, fatigue management should logically be an integral part of safety management systems. The Australian Maritime Safety Authority has developed useable guidelines to support fatigue risk management implementation in the maritime domain based on these guidelines.

\section{REFERENCES}

Dahl, O., Fenstad, J., \& Kongsvik, T. (2014). Antecedents of safety-compliant behaviour on offshore service vessels: A multi-factorial approach. Maritime Policy \& Management, 41(1), 20-41.

Grech, M., Horberry, T., \& Koester, T. (2008). Human factors in the maritime domain. CRC Press.

Griffin, M. A., \& Neal, A. (2000). Perceptions of safety at work: A framework for linking safety climate to safety performance, knowledge, and motivation. Journal of Occupational Health Psychology, 5, 347-358. doi:10.1037fl1076-8998.5.3.347

Griffin, M. A., \& Hu, X. (2013). How leaders differentially motivate safety compliance and safety participation: The role of monitoring, inspiring, and learning. Safety Science, 60, 196-202. 
Iverson, R. T. B. (2012). The mental health of seafarers. International Maritime Health 2012;63(2):78-89

Lawrie, M., Parker, D., \& Hudson, P. (2006). Investigating employee perceptions of a framework of safety culture maturity. Safety Science, 44(3), 259-276.

Lützhöft, M., Grech, M. R., \& Porathe, T. (2011). Information environment, fatigue, and culture in the maritime domain. Reviews of Human Factors and Ergonomics, 7(1), 280-322.

Neal, A., Griffin, M. A., \& Hart, P. M. (2000). The impact of organizational climate on safety climate and individual behavior. Safety Science, 34(1), 99-109.

Reason, J. (1997). Managing the risks of organizational accidents. Aldershot: Ashgate.

Roberts, S. E., \& Marlow, P. B. (2005). Traumatic work related mortality among seafarers employed in British merchant shipping, 1976-2002. Occupational and environmental medicine, 62(3), 172-180. 